\title{
Assessing the accessibility impact of transport policy by a land-use and transport interaction model - The case of Madrid
}

\author{
Yang Wang ${ }^{*}$, Andres Monzon ${ }^{1}$, Floridea Di Ciommo ${ }^{2}$ \\ Transport Research Centre (TRANSyT), Universidad Politecnica de Madrid, Calle Profesor Aranguren s/n, 28040 Madrid, Spain
}

\section{A R T I C L E I N F O}

\section{Article history:}

Available online $\mathrm{xxxx}$

Keywords:

Accessibility

LUTI model

Transport policy

\begin{abstract}
A B S T R A C T
Accessibility is an essential concept widely used to evaluate the impact of transport and land-use strategies in urban planning and policy making. Accessibility is typically evaluated by using separately a transport model or a land-use model. This paper embeds two accessibility indicators (i.e., potential and adaptive accessibility) in a land use and transport interaction (LUTI) model in order to assess transport policies implementation. The first aim is to define the adaptive accessibility, considering the competition factor at territorial level (e.g. workplaces and workers). The second aim is to identify the optimal implementation scenario of policy measures using potential and adaptive accessibility indicators. The analysis of the results in terms of social welfare and accessibility changes closes the paper.

Two transport policy measures are applied in Madrid region: a cordon toll and increase bus frequency. They have been simulated through the MARS model (Metropolitan Activity Relocation Simulator, i.e. LUTI model). An optimisation procedure is performed by MARS for maximizing the value of the objective function in order to find the optimal policy implementation (first best). Both policy measures are evaluated in terms of accessibility.

Results show that the introduction of the accessibility indicators (potential and adaptive) influence the optimal value of the toll price and bus frequency level, generating different results in terms of social welfare. Mapping the difference between potential and adaptive accessibility indicator shows that the main changes occur in areas where there is a strong competition among different land-use opportunities.
\end{abstract}

(c) 2014 Elsevier Ltd. All rights reserved.

\section{Introduction}

The concept of accessibility is widely used to evaluate the impact of land-use and transport strategies, and is becoming increasingly popular with the transition from 'catering for mobility' towards 'catering for accessibility' in urban planning and policy making (Bertolini et al., 2005; Condeço et al., 2011; Omer, 2006). Typically, accessibility is assessed by using transport or land-use models independently or successively without a feedback loop, thus overlooking the interaction effects between both systems (Geurs \& Van Wee, 2004; Geurs, Zondag, De Jong, \& De Bok, 2010). This is more than a mere methodological curiosity, as failure to account for land-use/transport interactions leads to a substantial underestimation in policy effects. For example, converting a city centre into a pedestrian-friendly zone affects the accessibility

\footnotetext{
* Corresponding author. Tel.: +34 9133667 08; fax: +34 913365362 .

E-mail addresses: wyang@caminos.upm.es (Y. Wang), amonzon@upm.es (A. Monzon), fdiciommo@caminos.upm.es (F.D. Ciommo).

1 Tel.: +34 9133653 73; fax: +34913365362.

2 Tel.: +34 9133652 33; fax: +34913365362.
}

and modal choice of road users (transport impacts), but may also have an effect on the attractiveness of the zone for new residents, workplaces and retail opportunities (land-use impact), which in turn increases transport demand in the area (i.e. a feedback loop).

The recent development of land-use and transport interaction (LUTI) models has led to a growing interest in their use for adequately evaluating accessibility (Badoe \& Miller, 2000; Geurs \& Van Wee, 2004; Geurs et al., 2010; Langford, Higgs, Radcliffe, \& White, 2008; Thill \& Kim, 2005). For example, Geurs et al. (2010) have estimated accessibility using a disaggregate log-sum method for trips at the individual level and calculated it in the utility function with a national LUTI model.

This paper follows this line of research in that it assesses accessibility using the LUTI model, but focuses on the aggregate level of accessibility changes by incorporating the competition effects of jobs due to the implementation of the transport policy. There are two aims associated with this objective. The first is to compute the Potential Accessibility (PA) by incorporating the effects of competition (Adapted Potential Accessibility, AA) using a LUTI model in order to estimate job opportunities - not only from the number of jobs within reach, but also from the competition for these jobs 
(Geurs \& Van Wee, 2004; Knox, 1978; Van Wee, Hagoort, \& Annema, 2001; Weibull, 1976). LUTI models are particularly suitable for assessing AA because the competition factor is a function of the number of jobs, which is related to land-use attractiveness and number of employees - among other factors-, and to transport demand (Van Wee et al., 2001). The second aim is to identify the optimal policy implementation value on the basis of the PA and the $A A$, and analyse the results in terms of social welfare. To the best of our knowledge, this paper is the first attempt to incorporate this effect of competition on accessibility in the objective function in order to find the maximum social welfare. The Madrid Region is used as a case study to present the new approach and to highlight the policy recommendations for urban planners and policy makers.

The LUTI model used in this study is the MARS (Metropolitan Activity Relocation Simulator) developed by Pfaffenbichler, Emberger, and Shepherd (2010). The MARS model represents the cause and effect relations between transport and land-use systems and integrates an optimisation algorithm for long-term policy making. The competition factor is embedded in the accessibility equation through the calculation of the AA. The optimisation procedure involves maximising the value of the objective function defined on the basis of cost benefit analysis (CBA), and includes not only the costs/benefits to road users, transport operators and government authorities, but also transport externalities of the whole society such as safety, environmental quality and land depletion.

Two policy measures - cordon toll and increased bus frequency - are optimised and evaluated by the MARS model. Cordon toll is a restrictive policy aimed at reducing car use in the congested metropolitan centre, while the increase in bus frequency as a substitute transport mode for the car would provide travellers with a better public transport (PT) option for travel around the whole of the Madrid metropolitan area.

The paper is organised as follows. Section 2 describes the methodology of the paper, including the features of the MARS model, the definition of the accessibility indicators with competition, the objective function and the optimisation procedures. Section 3 presents the current situation in Madrid and defines the scenarios. Section 4 compares the accessibility changes using the PA and the $\mathrm{AA}$, and analyses the results in terms of optimisation, derived social welfare, transport and land use impacts. The final section contains the conclusions.

\section{Methodology}

The proposed methodology consists of linking land-use and transport submodels by means of accessibility indicators. Fig. 1 shows the relations between the land-use/transport submodels and the accessibility indicators that are influenced by transport policies, and the optimisation procedure. The core of the relation between land-use and transport systems is the accessibility indicator, which is integrated in the model through the two submodels in the objective function affecting the optimisation procedure. The LUTI model estimates the accessibility changes to the scenarios conditioned by exogenous variables and policy measures; while the optimisation procedure -based on the CBA - maximises the objective function representing policy-makers' objectives.

\subsection{The MARS model}

The core concept of the MARS model is the adoption of the principles of System Dynamic (Sterman, 2000) and Synergetic (Haken, 1983). It is run in a SD (system dynamic) programming environment (VENSIM) based on causal loop diagrams (CLD), and represents the relation of cause and effect between the variables in the model (Shepherd et al., 2006). The MARS model was chosen for this study due to its ability to analyse the policy measures at the regional level, and because its structural flexibility allows the objective function to be modified.

MARS contains the transport submodel and the land-use submodel (Fig. 1). The transport submodel includes the first three stages of the common transport model (i.e. trip generation, trip distribution and modal split) and simplifies the road network into aggregate links for each origin-destination (OD) pair. It involves three travel modes: car, public transport (bus, metro, urban train) and walking. The congestion effect is recreated through speed-flow curves (Singh, 1999), in such a way that a higher number of trips results in a lower travel speed and vice versa (Pfaffenbichler et al., 2010).

The land-use submodel comprises a residential location submodel and a workplace location submodel. These two location submodels have a similar basic structure consisting of four further submodels: a development model, a willingness to move in model, a willingness to move out model and a supply/demand redistribution model. The willingness to move in/out submodels is influenced by the rent price, share of green land and accessibility level. Based on these two submodels (move in and move out), we can obtain the ratio of demanded/supplied housing utility for each zone. The demand would therefore be re-distributed if it is higher than the supply (Pfaffenbichler et al., 2010).

All the variables in MARS are interrelated through CLD relations. The exogenous variables such as demography (population, residents), economics (household income, household size) and land use (area, land-use type) etc., must be entered according to the case study. The interaction process is modelled using time-lagged feedback loops between the transport and land-use submodels over a long period (30 years for example) in one-year intervals. For this case study, the MARS model that comprise 90 zones based on administrative municipal has been calibrated by Guzmán (2011) using two household mobility surveys for the Madrid Region in 1996 and 2004 (CTRM, 1998, 2006).

\subsection{Accessibility indicators with competition}

Two accessibility indicators are applied in the MARS model: the traditional PA and the proposed AA that accounts for competition for jobs on the employment market. There are two reasons for incorporating competition effects with job accessibility: first, the policy measures considered here are aimed at encouraging modal shift during morning peak hours, when $65 \%$ of the trips are work-related. Secondly, work-related trips involve routine daily travel which is important when considering long-term regional economic growth, and therefore form the backbone of transport and land-use models. In this study, accessibility is defined only in terms of work trips.

The PA is widely used to measure the aggregate level of job accessibility, (Handy, 1994; Gutierrez, Monzón \& Piñero, 1998), and is estimated on a rigorous methodological basis (Koenig, 1980). PA combines the effect of transport/land use and incorporates assumptions regarding personal perceptions of transport by using a function that decreases with distance or time (Geurs \& Van Wee, 2004). Eq. (1) shows the typical form of PA (Hansen, 1959), which assumes a negative exponential cost function. The variable $t$ represents the period of time. The $i$ and $j$ are origin and destination zones respectively and $m$ represents the type of travel mode.

Potential accessibility : $P A_{i}(t)=\sum_{j m} W_{j m}(t) * F\left(t_{i j m}, c_{i j m}\right)$

where $P A_{i}$ is the potential accessibility of opportunities between $i$ and $j$ by mode $m$ in year $t, W_{j m}(t)$ is the opportunity to reach 


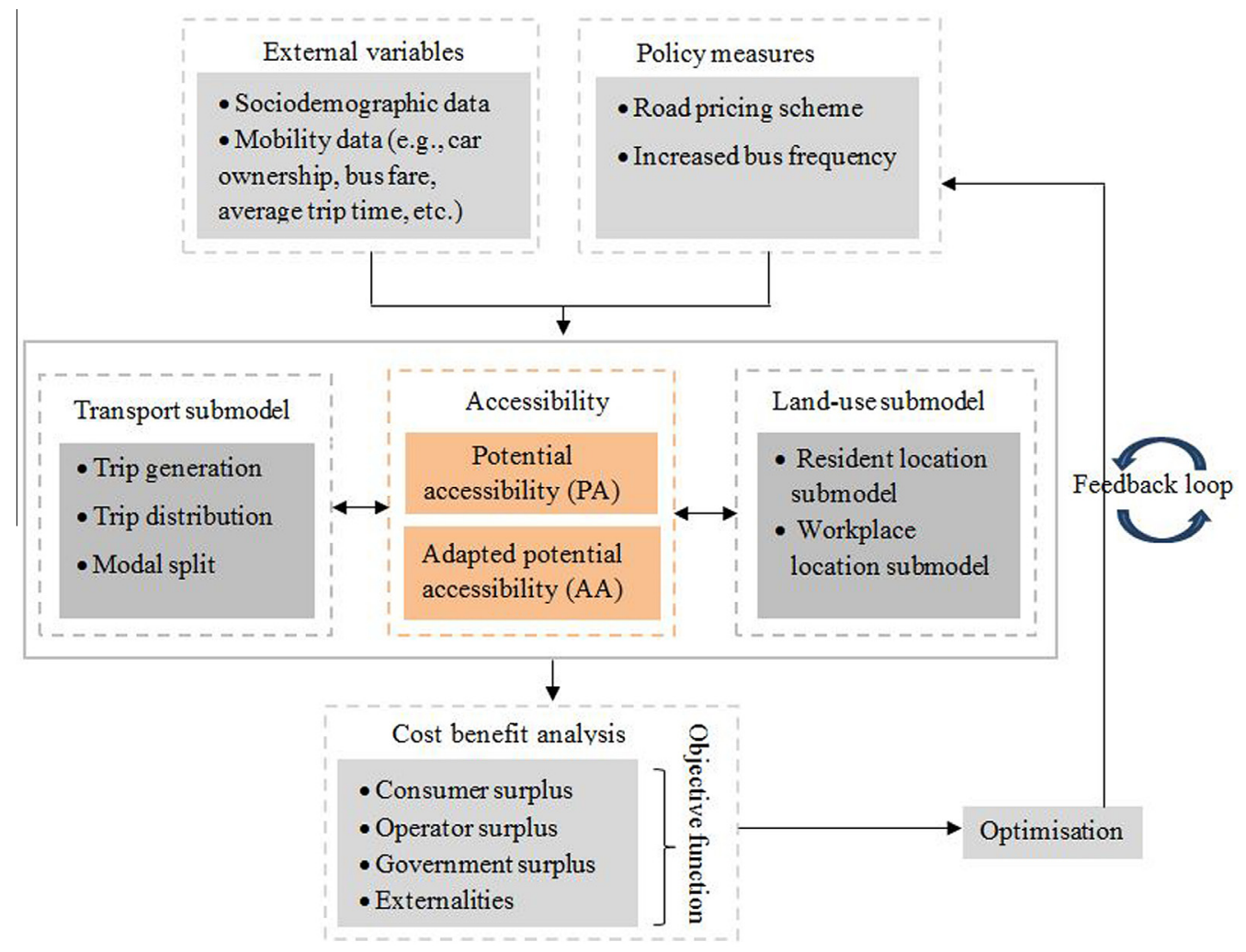

Basic structure of the evaluation and optimisation model $220 \mathrm{~mm} * 180 \mathrm{~mm}$ (300 DPI)

Fig. 1. Basic structure of the evaluation and optimisation model.

destinations in $j$ by mode $m$ in year $t, F\left(t_{i j m}, c_{i j m}\right)$ is a function of the average generalised travel cost associated with travel time and costs between $i$ and $j$ by mode $m$. For this study, the $F\left(t_{i j m}, c_{i j m}\right)$ is defined in Eq. (2) (Guzmán, Di Ciommo, \& De la Hoz, 2013):

$F\left(t_{i j m, c_{i j m}}\right)=0.16 * \operatorname{Exp}\left[-0.0163 *\left(c_{i j m}(t)+t_{i j m}(t)\right) * V O T\right]$

where $t_{i j m}(t)$ is the total travel time between $i$ and $j$ by mode $m$ in year $t ; c_{i j m}(t)$ is the total travel cost between $i$ and $j$ by mode $m$ in year $t$; VOT is the value of time ( $€ 10.45 / \mathrm{h}$ during peak hours and $€ 5.7 / \mathrm{h}$ during non-peak hours). The parameters in Eq. (2) were calibrated by Guzmán (2011) on the basis of two household mobility surveys in Madrid (CTRM, 1998,2006).

However, the PA has a theoretical shortcoming in that it excludes competition effects (Geurs \& Van Wee, 2004). When there is high competition for jobs in the area, the chance of obtaining the job is lower than in a situation with no or less competition. We therefore suggest an accessibility indicator based on the PA but modified by means of the competition effect on the employment market.

There are several ways to incorporate the competition effects (Geurs \& Van Wee, 2004) in the PA (Joseph \& Bantock, 1982; Van Wee et al., 2001; Weibull, 1976; Geurs and Ritsema van Eck, 2003). In this study, the competition factor for jobs in destination $j$ (represented by $G_{j}^{t}$ ) is expressed by the ratio between the number of jobs (job supply) $\left.W_{j}(t)\right)$ at destination $j$ in year $t$ and the number of employees $E_{j}(t)$ who reside in the same zone $j$ in year $t$ (job demand) (Van Wee et al., 2001); see Eq. (3).

Competition factor : $G_{j}(t)=\frac{W_{j}(t)}{E_{j}(t)}=\frac{W_{j}(t-1)+m_{j}(t)}{E_{j}(t-1)+n_{j}(t)}$

where $m_{j}(t)$ is the change in the number of jobs in zone $j$ in year $t$, which is the number of jobs generated in year $t$ subtracting the number of jobs that ceased to exist in year $t$, and $n_{j}(t)$ is the change in the number of employees residing in zone $j$ in year $t$ and is decided by the number of employees who entered the labour market minus the number who left the labour market in year $t$. Both $W_{j}(t)$ and $E_{j}(t)$ are defined in the land-use submodel of MARS. The change in the competition factor is induced by the implementation of transport policy measures. By including this competition factor, the definition of the AA is given in Eq. (4).

$$
\begin{aligned}
& \text { Adapted potential accessibility : } A A_{i}(t) \\
& =\sum_{j m} G_{j}(t) * W_{j m}(t) * F\left(t_{i j m}, c_{i j m}\right)
\end{aligned}
$$

where $W_{j m}(t)$ and $F\left(t_{i j m}\right.$, cijm $)$ are defined as in the $P A$ indicator, and $G_{\mathrm{j}}(t)$ represents the competition factor in zone $j$.

\subsection{The role of accessibility in the MARS model}

Fig. 2 shows the simplified CLD of the PA and AA in MARS, as defined in this study. The change in jobs is determined by the input/output flow of jobs in zone $j$ (i.e. the difference between the jobs attracted to zone $j$ and the jobs that migrate from zone $j$ to other zones). There is a mutual influence between job supply and $A A$, as the job supply in each zone is also influenced by its accessibility, in addition to the variables in land-use submodels (such as land price, land-use development opportunities, and employment sector growth rate). As with the job supply, there is a mutual influence between job demand (number of employees) (i.e., the input/output flow of employees) and AA, because accessibility is one of the main determinants of job demand and residential growth. 


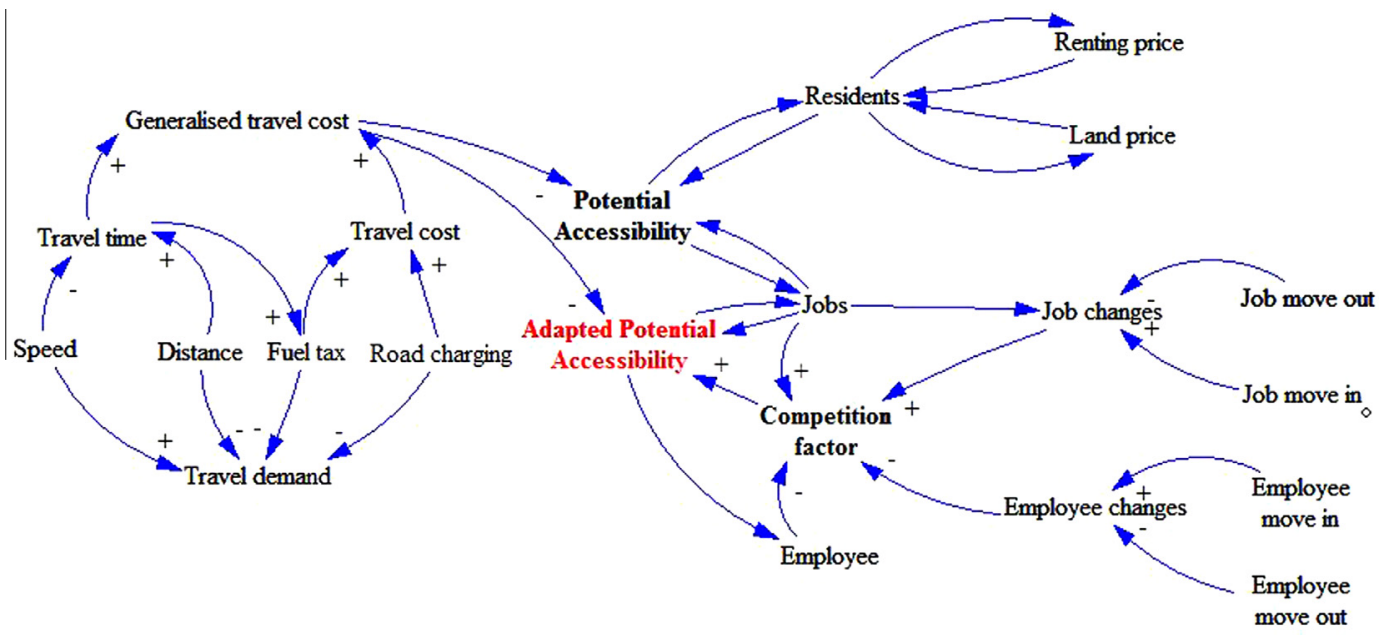

Simplified CLD of accessibility indicators in the MARS model

$230 \mathrm{~mm} * 120 \mathrm{~mm}$ (300 DPI)

Fig. 2. Simplified CLD of accessibility indicators in the MARS model.

The two accessibility indicators (PA and AA) are implemented in the MARS model using the interaction between transport and the different land-use submodels. The AA including the competition factor integrates more mutual influences from the land-use submodels. Therefore, AA would be a more accurate indicator than PA for representing differences in competition for jobs among zones after the implementation of transport policy measures.

\subsection{Optimisation}

The objective function for social welfare embedded in the optimisation procedure is based on a dynamic CBA. For each proposed policy measure, it defines the variable denoted 'policy profile' with different characteristics. The policy profile variable is based on the value of $P s$ (policy start value, when the policy is introduced) to Pe (policy end value, when it finishes) as the levels of policy attributes respectively in the initial year Ts when the policy is introduced (i.e., 2012) and in the long-run year Te at the end of the evaluation (i.e. 2034), as show in Eq. (5).

Policy $(t, z)=\left(\begin{array}{cc}\frac{P_{e}-P_{s}}{t-T_{s}}, & t>T_{s} \text { and } t<T_{e}, z<Z^{\prime} \\ 0, & t<T_{s} \text { or } z>Z^{\prime}\end{array}\right)$

ehere $t$ is current run year and $z$ is zone number in MARS. When the current run year $t$ is greater than the initial year $T s$, and the zone number $z$ is less than the zones $Z^{\prime}$ defined for policy implementation, the policy instrument is implemented. As seen in Eq. (5), the policy will stop when the current year $t$ is after the defined end year $T e$. And during the optimisation process, the variables of policy start value $P s$ and end value $P e$ change to get the maximum welfare.

Considering the large number of parameters to be calibrated and the nonlinear interactions, the optimisation method must be efficient in terms of its calculation time. Direct methods of linear optimisation cannot be used due to the complexity of the mathematical models for dynamic systems (Yücel \& Barlas, 2007). Dynamic systems require optimisation methods that are not based on a precise calculation of the derivatives (Janamanchi \& Burns, 2007; Lewis, Torczon, \& Trosset, 2000). The Powell algorithm (Powell, 1964) overcomes these shortcomings and can thus be applied in the MARS model to maximise the objective welfare function within specified boundary values without the need to calculate partial derivatives. A detailed description of the algorithm is provided by Brent (1973) and Press, Teukolsky, Vetterling, and Flannery (1992).

\subsection{Objective function of social welfare}

The objective function (OF) based on the CBA calculates the social welfare differences between the base scenario and the policy scenario for the two travel modes (car and PT). The change in social welfare includes the sum of all social benefits optimised throughout the entire time period for all zones, and has the following four components: consumer surplus, operator and government surplus (costs and benefits), and externalities. Eq. (6) shows the definition of the OF (Guzmán et al., 2013).

$$
\begin{aligned}
\Delta W(U)= & \int_{0}^{n} \sum_{i j m} \frac{1}{(1+r)^{t}}\left[\Delta C S_{i j m}(t)+\Delta O_{i j m}(t)+\Delta G O_{i j m}(t)\right. \\
& \left.+\Delta E_{i j m}(t)\right] d t
\end{aligned}
$$

The analysis of the OF is expressed by the net present value (NPV) over the entire evaluation period, using a social discount rate of $r=4.8 \%$ (Souto Nieves, 2003). As above, variable $t$ represents the period of time. The $i$ and $j$ subscripts are the origin and destination zones respectively, and $m$ represents the travel mode.

The disaggregated welfare function for transport users (consumer surplus, CS) is given by Eq. (7):

$$
\begin{aligned}
\Delta C S(t)= & \frac{1}{2} \sum_{t} \sum_{i j m}\left[T_{i j m}^{0}(t)+T_{i j m}^{1}(t)\right] \cdot\left(c_{i j m}^{1}(t)+t_{i j m}^{t} \cdot V O T_{i}\right. \\
& \left.-c_{i j m}^{0}(t)-t_{i j m}^{0} \cdot V O T_{i}\right)
\end{aligned}
$$

where $T_{i j m}^{k}(t)$ is the demand for trips between $i$ and $j$ by mode $m$, in the $k$ scenario; $C_{i j m}^{k}(t)$ is total travel cost including road charging and operation cost; $\mathrm{t}_{i j m}^{k}(t)$ is the travel time; and VOT is the value of time. The superscript $k$ is used to denote either the base scenario $(k=0)$ or the policy scenario defined $(k=1)$.

The operators' cost is calculated by Eq. (8) and shows the value of net benefits to operators, including public transportation (PT) fares and toll and parking revenues (17).

$$
\Delta O(t)=\sum_{t} \sum_{i j m} T_{i j m}^{1}(t) \cdot\left[\beta_{i j m}^{1}(t)+a_{i j m}^{1}(t)\right]-T_{i j m}^{0}(t) \cdot\left[\beta_{i j m}^{0}+a_{i j m}^{0}(t)\right]
$$

where $\beta_{i j m}^{k}(t)$ is the revenue of private vehicles in the case of an urban toll or parking charge fee and the revenue collected from PT services, e.g. trip tickets, while $a_{i j m}^{k}(t)$ represents the cost of administration, operation and maintenance. 
Eq. (9) represents the benefits or costs to government resulting from changes in fuel tax revenue $\left(\Delta F_{i j}\right)$ and the variation in road maintenance cost $\left(\Delta M_{i j}\right)$.

$\Delta G(t)=\sum_{t} \sum_{i j m}\left[T_{i j m}^{1}(t)-T_{i j m}^{0}(t)\right] \cdot\left[F_{i j m}+M_{i j m}\right]$

Finally, Eq. (10) represents the value of external costs, associated to green-house gas emissions $\left(\Delta G H E_{i j}\right)$, air pollution $\left(\Delta P_{i j}\right)$, road safety $\left(\Delta S_{i j}\right)$ and land-use costs $\left(\Delta L_{i j}\right)$.

$$
\begin{aligned}
\Delta E(t)= & \sum_{t} \sum_{i j m}\left[T_{i j m}^{1}-T_{i j m}^{0}\right] \cdot\left[G H E_{i j m}(t)+P_{i j m}(t)+S_{i j m}(t)\right. \\
& \left.+L_{i j m}^{t}\right]
\end{aligned}
$$

Fig. 1 shows that although the accessibility indicator is not directly included in the $\mathrm{OF}$, it is influenced reciprocally by the transport submodel (i.e., generalised travel costs) and the landuse submodel (e.g., number of jobs, house prices, etc.). The number of trips interacts with all four components of the OF by influencing, among other factors, the number of jobs and employees, and house prices. Compared to PA, AA has a higher sensitivity to zone attractiveness, leading to different NPVs. The two accessibility indicators thus influence the OF towards achieving the optimal level for each policy measure.

\section{The case study of Madrid}

\subsection{Transport and population in Madrid}

The Madrid Region had a population of 6.5 million inhabitants in 2011, and covers an area of $8030 \mathrm{~km}^{2}$. As depicted in Fig. 3, the Madrid Region as a whole consists of three distinct areas: the city of Madrid, the metropolitan ring and the outermost ring, known as the regional ring. The population distribution in the region varies between extremely low density in the outer ring to extremely high density in the metropolitan ring (INE, 2011).

Current demographic trends show a population decline in the metropolitan ring and a population growth in the suburbs of Madrid city and the regional ring, leading to a steady decline in the weight of the metropolitan core area from $65 \%$ to $52 \%$ between 1985 and 2006, respectively (Di Ciommo et al., 2011). Land-use development policies have induced low densities and urban sprawl, thus encouraging a car-oriented urban lifestyle.

Household mobility surveys (CTRM, 1998, 2006) show that from 1996 to 2004 the number of motorised trips increased by $52 \%$, whereas the population increased by only $14 \%$ (Monzón \& De la Hoz, 2009). Indeed, the motorisation rate in Madrid is the highest in Spain, with 529 per ,000 inhabitants and a yearly growth rate of $7 \%$. Some $45 \%$ of the daily 14.51 million trips and $35 \%$ of the work trips are done by car, whereas $32 \%$ of the work trips use PT. Even though the PT system in Madrid is one of the most efficient in Europe, the sprawling tendency makes it difficult to offer good public services outside the city of Madrid and increases the need for car use (Di Ciommo et al., 2011).

\subsection{Scenario definition}

Two policy scenarios are designed to reduce car use: a cordon toll scenario and a combination of cordon toll and higher bus frequency, and these two scenarios are investigated in comparison with the base scenario. Both policy scenarios are implemented from 2012 to 2034. The planning horizon ends in 2034 because the MARS model was calibrated for Madrid using the mobility data obtained in 2004, and the planning horizon was set at between 2004 and 2034.

The base scenario of do-nothing (S0) includes all infrastructures that were already built by 2012 and no later interventions are considered during the evaluation period. All the exogenous variables (i.e., demography, economics, land use, etc.) are contained in the

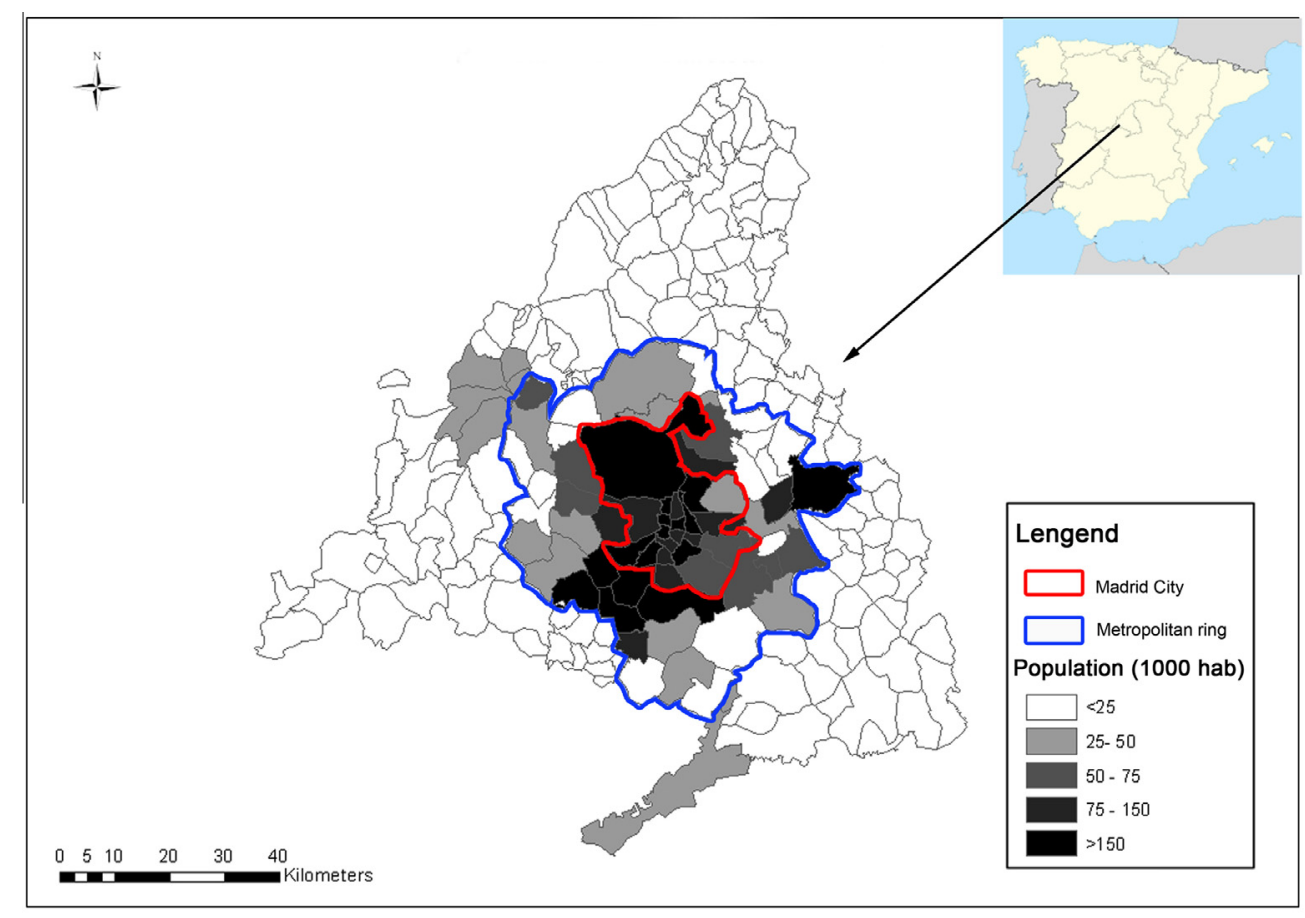

Population distribution in the Madrid Region (Source: INE, 2011) $220 \mathrm{~mm} * 170 \mathrm{~mm}(300 \mathrm{DPI})$

Fig. 3. Population distribution in the Madrid Region. (Source: INE, 2011). 
Table 1

Scenario descriptions.

\begin{tabular}{|c|c|c|c|c|c|c|}
\hline Scenarios & Scenario description & Policy measure & Initial year & Final year & Lower bound & Upper bound \\
\hline So & Do-nothing & No policy implementation & 2012 & 2034 & 0 & 0 \\
\hline S1 & Single policy scenario & Cordon toll: Access to M-40 & 2012 & 2034 & $0 € /$ veh & $10 € /$ veh \\
\hline S2 & Combined policy scenario & $\begin{array}{l}\text { Cordon toll: Access to } \mathrm{M}-40 \\
\text { Increased bus frequency: Whole metropolitan area }\end{array}$ & 2012 & 2034 & $\begin{array}{l}0 € / \text { veh } \\
0 \%\end{array}$ & $\begin{array}{l}10 € / \text { veh } \\
100 \%\end{array}$ \\
\hline
\end{tabular}

policy scenarios (Guzmán, 2011). Under scenario S0, the net social welfare is set to zero.

A single cordon toll scenario (S1) is the application of a cordon toll to commute trips during peak hours on one of Madrid's orbital highways (M-40). The toll scheme is implemented only for private cars entering the cordon area (single entry charging).

A combined policy scenario (S2) integrates a cordon toll and increased bus frequency. The cordon toll is implemented on the access to the $\mathrm{M}-40$ as in $\mathrm{S} 1$, and the increased bus frequency is applied inside the metropolitan area during peak hours.

For each scenario, the calculations are made with the two accessibility indicators (PA and $A A$ ). The optimisation process is thus applied to six scenarios: S0 with PA and AA, S1 with PA and AA, and S2 with PA and AA. The toll price and bus frequency levels vary throughout the time period, with intermediate values determined by interpolation between the start year and the end year levels. The cordon toll rate and level of bus frequency increase are both obtained by maximising the NPV of the proposed OF compared to S0. The MARS model requires the definition of upper and lower bounds in order to find the optimal solution within the range of feasible values. In this study, the lower/upper bound of the cordon toll is defined considering the existing toll fee in London ( $£ 10$ per vehicle) between $€ 0$ per vehicle and $€ 10$ per vehicle. The range for the increase in bus frequency is established considering operating cost restrictions (Guzman et al., 2013). The description of the three scenarios is given in Table 1 .

\section{Analysis of results}

\subsection{Accessibility as a quality indicator}

The first group of results is related to the accessibility levels for both car and PT trips when applying the different policy measures. Table 2 shows the results for three areas of Madrid, namely the cordon charging area, the increased bus frequency area (also the metropolitan area of Madrid) and the regional periphery. All these results correspond to the final year 2034. The results include:

- the average competition factor (CF),

- the difference in the base scenario for the run with PA and AA,

- the changes in accessibility in the two policy scenarios (S1 and $\mathrm{S} 2$ ) in comparison with the base scenario (S0) using PA or AA respectively.

As expected, the average $\mathrm{CF}$ is higher when it approaches the cordon toll area (i.e. the CBD area) as seen in Fig. 4 which shows the $\mathrm{CF}$ distribution in the region of Madrid for the planning horizon (2034). This reveals that Madrid's metropolitan ring is a relatively high competitive area for jobs in comparison with the periphery of the region. The most competitive zones are located mainly in the CBD area, which is highly attractive to employers. Some of the municipalities in the metropolitan area also have high competition due to their industrial agglomeration, which produces more jobs. The rest of the Madrid region has lower competition owing to its lower population density (i.e. job demand), as shown in Fig. 3.
Table 2

Accessibility results in the three areas.

\begin{tabular}{|c|c|c|c|c|c|c|}
\hline \multirow[t]{2}{*}{ Three areas } & \multirow[t]{2}{*}{$\begin{array}{l}\text { Average } \\
\text { competition } \\
\text { factor }\end{array}$} & \multirow[t]{2}{*}{$\begin{array}{l}\text { Accessibility in } \\
\text { base scenario } \\
\text { (PA/AA) }\end{array}$} & \multicolumn{2}{|c|}{$\begin{array}{l}\text { Accessibility } \\
\text { changes } \\
\text { using PA }\end{array}$} & \multicolumn{2}{|c|}{$\begin{array}{l}\text { Accessibility } \\
\text { changes } \\
\text { using AA }\end{array}$} \\
\hline & & & $\mathrm{S} 1 / \mathrm{S} 0$ & $\mathrm{~S} 2 / \mathrm{S} 0$ & $\mathrm{~S} 1 / \mathrm{S} 0$ & $\mathrm{~S} 2 / \mathrm{S} 0$ \\
\hline Cordon charging area & 1.02 & $-3 \%$ & $-12 \%$ & $-4 \%$ & $-12 \%$ & $-5 \%$ \\
\hline $\begin{array}{l}\text { Increased bus } \\
\text { frequency area }\end{array}$ & 0.62 & $31 \%$ & $1 \%$ & $5 \%$ & $2 \%$ & $8 \%$ \\
\hline Regional periphery & 0.53 & $37 \%$ & $1 \%$ & $4 \%$ & $1 \%$ & $5 \%$ \\
\hline
\end{tabular}

The difference between the base scenario and the run with the PA and the AA indicates that total accessibility is higher using PA in the metropolitan area ( $31 \%$ more) and in the regional periphery (37\% more), which leads to higher travel demand and house prices.

Total changes in accessibility after the application of the policy measures reveal that accessibility inside the cordon area is reduced owing to higher travel costs, and increased in the bus frequency area and the regional periphery using both PA and AA. However, there was a greater increase in accessibility when using AA than PA in the case of S2, where the toll was combined with higher bus frequency.

Fig. 5 shows the differences in total accessibility changes (i.e., $\mathrm{S} 1-\mathrm{SO}$ and S2-S0) in the whole Madrid region using PA and AA respectively, and highlights the effect of the competition factor in the long term. The figure shows that while there is a small difference in the S1 (Fig. 5, upper part), the difference is greater in terms of geographical scope in the S2 (Fig. 5, lower part).

Comparing the S1 with S0, the accessibility decreases in the tolled area as a result of higher travel costs, and slightly increases in the spillover areas of the cordon toll. A comparison of the accessibility calculated by PA and AA reveals a similar downward trend in accessibility in the cordon toll area. However, the AA indicator shows higher accessibility values in areas with a higher competition factor such as the southern part of the metropolitan area or in the northwest, where a greater number of workplaces are located.

The difference between S2 and S0 shows that accessibility decreases in the cordon toll area and increases where bus frequency rises. The major changes between PA and AA are detected in the higher competitive zones, not only in the CBD but also in the northern and southern areas of Madrid. Consequently, the zones that have less competition in terms of activity (mainly in the areas that are far from the city centre) produce similar results between $\mathrm{AA}$ and PA, while significant differences can be seen in the more competitive zones.

\subsection{Optimisation results}

The optimisation process generated the optimal values for the intensity of the implementation of the measures for the startyear/end-year by using PA and AA respectively (Table 3).

There is a minor difference in $\mathrm{S} 1$ in the optimal results between $\mathrm{PA}$ and $\mathrm{AA}$, but for $\mathrm{S} 2$ the difference in the end value is significant (€4.02/veh versus $€ 5.45 /$ veh). 


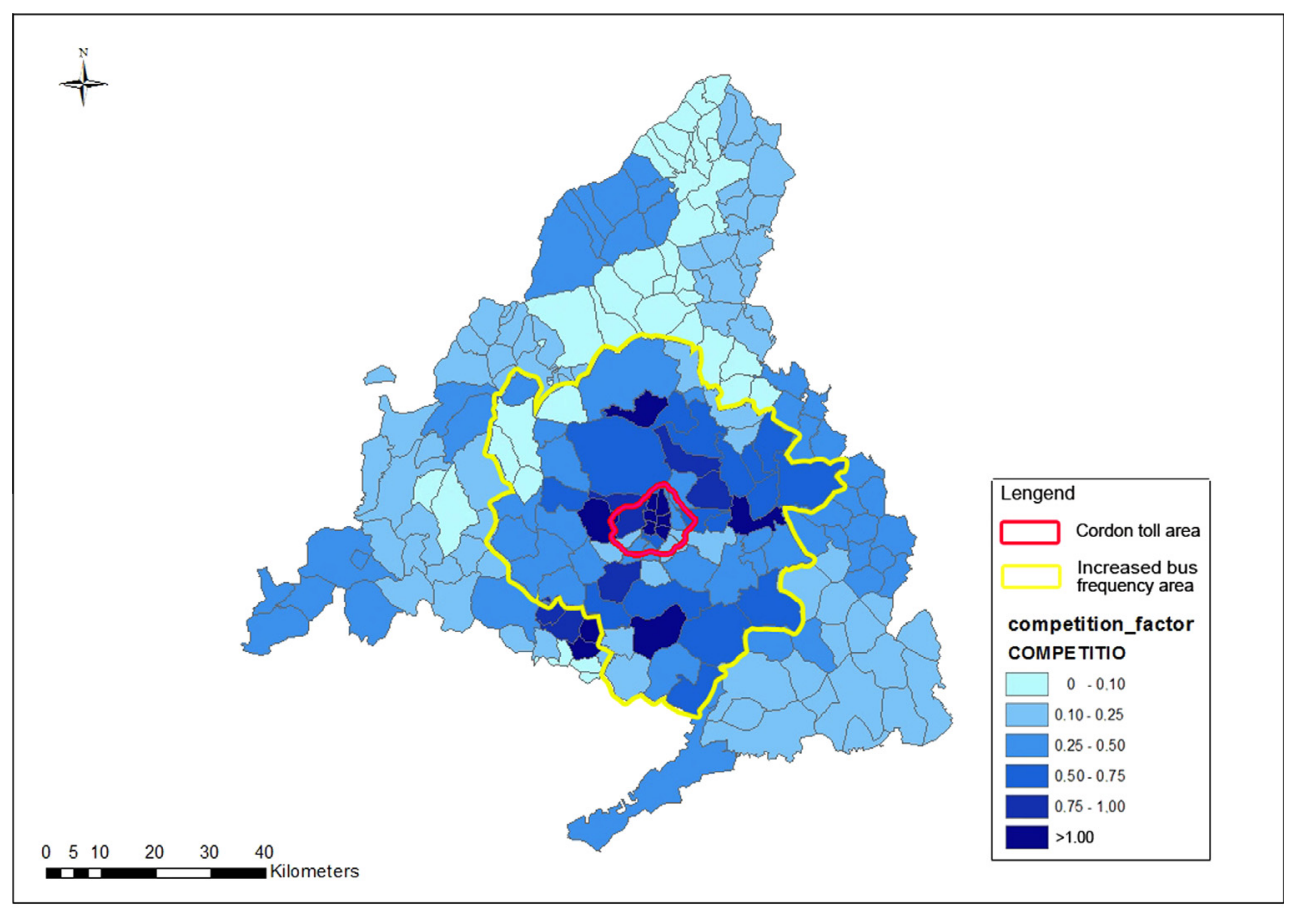

Competition factor among the three areas $300 \mathrm{~mm} * 210 \mathrm{~mm}(300 \mathrm{DPI})$

Fig. 4. Competition factor among the three areas.

\begin{tabular}{|c|}
\hline Legend \\
Total_Acc \\
$<-1000$ \\
$-1000-500$ \\
$-500--200$ \\
$-200-0$ \\
$0-50$ \\
\\
$\quad 50$ \\
\hline
\end{tabular}

Accessibility Changes (S1-S0) by PA

Accessibility Changes (S1-S0) by AA

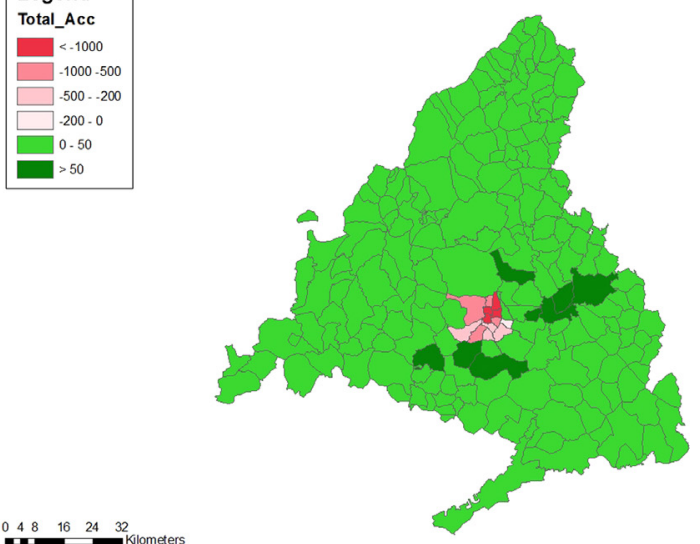

$1.16-24$ Kilometers

$+$

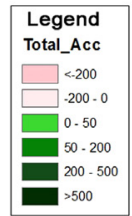

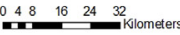

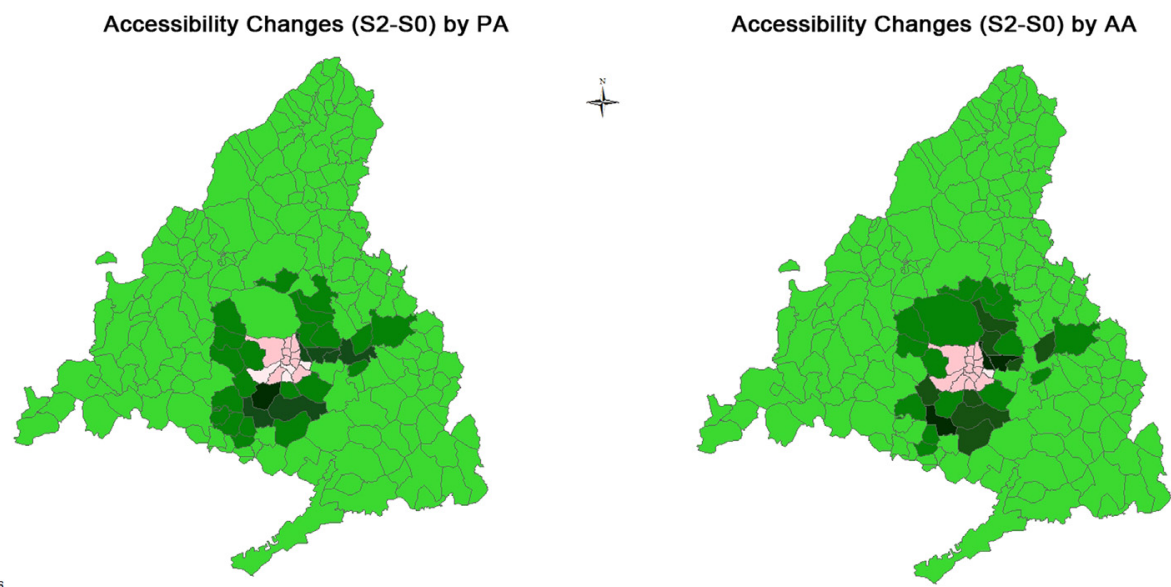

Accessibility changes between $\mathrm{S} 1 / \mathrm{S} 2$ and $\mathrm{S} 0$ by AA-PA

$250 \mathrm{~mm} * 220 \mathrm{~mm}(300 \mathrm{DPI})$

Fig. 5. Accessibility changes between $\mathrm{S} 1 / \mathrm{S} 2$ and S0 by AA-PA.

Please cite this article in press as: Wang, Y., et al. Assessing the accessibility impact of transport policy by a land-use and transport interaction model - The case of Madrid. Computers, Environment and Urban Systems (2014), http://dx.doi.org/10.1016/j.compenvurbsys.2014.03.005 
Table 3

Results of optimisation according to scenario by the two accessibility indicators.

\begin{tabular}{|c|c|c|c|c|c|}
\hline \multirow[t]{2}{*}{ Scenario } & \multirow[t]{2}{*}{ Policy measure } & \multicolumn{2}{|c|}{ Using potential accessibility } & \multicolumn{2}{|c|}{ Using adapted potential accessibility } \\
\hline & & Start value & End value & Start value & End value \\
\hline So & Do nothing & 0 & 0 & 0 & 0 \\
\hline S1 & Cordon toll & $€ 4.98 /$ veh & $€ 5.00 /$ veh & $4 € .91 /$ veh & $€ 4.97 /$ veh \\
\hline \multirow[t]{2}{*}{ S2 } & Cordon toll & $€ 5.33 /$ veh & $€ 4.02 /$ veh & $€ 5.04 /$ veh & $€ 5.45 / v e h$ \\
\hline & Increased bus frequency & $25.2 \%$ & $18.0 \%$ & $23.4 \%$ & $22.0 \%$ \\
\hline
\end{tabular}

Table 4

Transport and land-use impacts in the three areas.

\begin{tabular}{|c|c|c|c|c|c|c|c|}
\hline \multirow[t]{2}{*}{ Variable } & \multirow[t]{2}{*}{ Accessibility indicator } & \multicolumn{2}{|c|}{ Cordon charging area } & \multicolumn{2}{|c|}{ Increased bus frequency area } & \multicolumn{2}{|c|}{ Regional periphery } \\
\hline & & $\mathrm{S} 1 / \mathrm{S} 0$ & $\mathrm{~S} 2 / \mathrm{S} 0$ & $\mathrm{~S} 1 / \mathrm{S} 0$ & $\mathrm{~S} 2 / \mathrm{S} 0$ & $\mathrm{~S} 1 / \mathrm{S} 0$ & $\mathrm{~S} 2 / \mathrm{S} 0$ \\
\hline Car trip reduction $\left(10^{3}\right)$ & $\begin{array}{l}\mathrm{PA} \\
\mathrm{AA}\end{array}$ & $\begin{array}{l}-3.5 /-0.8 \% \\
-3.3 /-0.7 \%\end{array}$ & $\begin{array}{l}-24.0 /-5.3 \% \\
-18.8 /-4.1 \%\end{array}$ & $\begin{array}{l}-29.3 /-4.0 \% \\
-25.7 /-3.5 \%\end{array}$ & $\begin{array}{l}-49.8 /-6.8 \% \\
-36.3 /-4.9 \%\end{array}$ & $\begin{array}{l}-2.6 /-1.3 \% \\
-2.2 /-1.2 \%\end{array}$ & $\begin{array}{l}-9.2 \mid-4.7 \% \\
-6.6 /-3.4 \%\end{array}$ \\
\hline Car speed increase $(\mathrm{km} / \mathrm{h})$ & $\begin{array}{l}\mathrm{PA} \\
\mathrm{AA}\end{array}$ & $\begin{array}{l}52.8 / 1.2 \% \\
53.1 / 1.4 \%\end{array}$ & $\begin{array}{l}54.0 / 3.5 \% \\
54.7 / 4.6 \%\end{array}$ & $\begin{array}{l}54.1 / 1.7 \% \\
54.3 / 1.9 \%\end{array}$ & $\begin{array}{l}55.2 / 3.8 \% \\
56.1 / 5.0 \%\end{array}$ & $\begin{array}{l}53.9 / 1.3 \% \\
54.2 / 1.5 \%\end{array}$ & $\begin{array}{l}55.0 / 3.4 \% \\
55.7 / 4.4 \%\end{array}$ \\
\hline Bus speed increase $(\mathrm{km} / \mathrm{h})$ & $\begin{array}{l}\mathrm{PA} \\
\mathrm{AA}\end{array}$ & $\begin{array}{l}42.8 / 1.0 \% \\
43.0 / 1.1 \%\end{array}$ & $\begin{array}{l}43.0 / 1.4 \% \\
44.0 / 3.7 \%\end{array}$ & $\begin{array}{l}43.9 / 1.4 \% \\
44.1 / 1.5 \%\end{array}$ & $\begin{array}{l}44.1 / 1.9 \% \\
45.2 / 4.1 \%\end{array}$ & $\begin{array}{l}44.1 / 1.1 \% \\
44.3 / 1.2 \%\end{array}$ & $\begin{array}{l}44.2 / 1.5 \% \\
45.3 / 3.7 \%\end{array}$ \\
\hline Increase in jobs $\left(10^{3}\right)$ & $\begin{array}{l}\mathrm{PA} \\
\mathrm{AA}\end{array}$ & $\begin{array}{l}0 / 0 \% \\
0 / 0 \%\end{array}$ & $\begin{array}{l}0 / 0 \% \\
0 / 0 \%\end{array}$ & $\begin{array}{l}10.2 / 0.7 \% \\
13.2 / 0.6 \%\end{array}$ & $\begin{array}{l}14.6 / 1.0 \% \\
18.3 / 0.3 \%\end{array}$ & $\begin{array}{l}0.8 / 1.0 \% \\
0.9 / 0.5 \%\end{array}$ & $\begin{array}{l}0.4 / 1.4 \% \\
0.6 / 0.5 \%\end{array}$ \\
\hline
\end{tabular}

Table 5

Surplus of each scenario with the two accessibility indicators ( $€$ millions).

\begin{tabular}{|c|c|c|c|c|}
\hline \multirow[t]{2}{*}{ Scenario } & \multicolumn{2}{|l|}{ Using PA } & \multicolumn{2}{|l|}{ Using $\mathrm{AA}$} \\
\hline & S1-S0 & S2-S0 & S1-S0 & S2-S0 \\
\hline \multicolumn{5}{|l|}{ Indicator } \\
\hline NPV Social welfare & 582.28 & 948.29 & 665.89 & 1045.31 \\
\hline NPV consumer surplus & -1419.23 & -132.03 & -1315.21 & -35.93 \\
\hline Car users & -1586.13 & -862.24 & -1507.35 & -842.69 \\
\hline Toll and parking costs & -2093.74 & -2368.5 & -2278.06 & -2517.27 \\
\hline Operation cost savings & 37.98 & 110.88 & 57.73 & 123.51 \\
\hline Travel time savings & 469.76 & $1,395.40$ & 713.32 & 1563.16 \\
\hline Public transport users & 166.68 & 730.18 & 192.12 & 806.76 \\
\hline Travel time savings & 166.68 & 730.18 & 192.12 & 806.76 \\
\hline NPV Operator surplus & 1862.12 & 1032.30 & 2033.02 & 1222.34 \\
\hline Toll revenues & 1798.21 & 1716.24 & 1937.02 & 1929.30 \\
\hline Bus ticket revenues & 64.11 & 242.19 & 95.52 & 287.66 \\
\hline PT operation costs & 0 & -926.64 & 0 & -994.86 \\
\hline NPV Government surplus & -39.16 & -98.31 & -70.42 & -134.22 \\
\hline Fuel tax revenues & -38.31 & -104.01 & -76.24 & -146.92 \\
\hline Road maintenance costs & -0.85 & 5.70 & 5.82 & 12.70 \\
\hline NPV external surplus & 179.10 & 146.63 & 18.53 & -6.48 \\
\hline Accident cost & -105.89 & -166.03 & -86.86 & -154.61 \\
\hline Environment benefits & 9.80 & 6.13 & 18.68 & 14.54 \\
\hline Land use benefits & 275.19 & 306.53 & 86.71 & 133.59 \\
\hline
\end{tabular}

The reason for this result is that the AA indicator detects higher accessibility in more competitive areas (inside the $\mathrm{M}-40$ for example), and lower accessibility in less competitive areas. Since high accessibility increases the attractiveness of trips, it expands the difference between number of trips in high and low competitive areas. With the increased bus frequency in S2, a number of travellers shift from private vehicles to PT (see Table 4). The figure for car users is lower with the PA than with the AA in the more competitive areas where a cordon toll is implemented. A higher end value of cordon toll is needed in order to maintain the surplus in car users even when the AA indicator is used.

Moreover, the optimal start/end values of bus frequency decrease with AA throughout the evaluation period (from $23.4 \%$ to $22 \%$ ) in S2. The results of the calculation are mainly determined by the trade-off between operator and consumer surplus. Since consumer surplus increases with the rise in bus frequency, operator surplus decreases due to higher operating costs. The weight of the bus operator surplus in the long term is higher, and consequently the level of bus frequency is reduced in the end year of the simulation (Guzman et al., 2013).

\subsection{Impacts on transport and land use}

The impact on transport due to the implementation of policies is shown by the reduction in car trips and the increase in average vehicle speed (for both car and bus). The greater number of jobs produces an impact on the land-use system. Table 4 shows these results for the end year 2034 for the three areas (Fig. 4) differentiated by PA and AA. 
The results present the increase/decrease variable and the percentage of change.

S2 is more efficient than S1 in reducing car trips, increasing vehicle speed and generating new jobs for both PA and AA. Considering the different impacts on transport and land use with PA and AA, we find that:

(1) reduction in car trips is greater with PA than with AA;

(2) the average speed (car and bus) representing the level of congestion mitigation is lower with PA than AA, especially in $\mathrm{S} 2$;

(3) the results produced by AA generate more jobs from the policy measure than PA, particularly in the area with increased bus frequency, i.e. more than ten thousand jobs are generated as results of overall increased productivity in the area between the $\mathrm{M}-40$ and the metropolitan ring.

This result is related to the fact that the AA indicator reveals the changes in both job supply and demand at the Madrid region level, and is thus more sensitive to transport and land-use changes after the application of a policy measure.

\section{4. $C B A$ results}

Using the optimisation results as an input in MARS, we simulated each scenario progressively beginning with the start value and concluding with the end year value. The results of the CBA are shown in Table 5. The NPV are the sum of all social benefits optimised across all zones and for the whole time period between 2012 and 2034. The results represent the difference between each policy scenario and the base scenario using AA and PA respectively.

The NPV social welfare is higher in S2 than in S1 regardless of whether PA or AA is used, which implies that the combined policy achieves a better result in both cases. The CBA results with PA and AA reveal that the choice of accessibility calculated in the model induces a significant difference in two main elements of the OF: consumer surplus and land use benefits.

This difference in consumer surplus is because the PA tends to produce a higher accessibility level in less competitive zones, and thus the number of trips is also higher when using the PA in comparison with the AA (see Table 4). Therefore the decline in consumer surplus is greater when using the PA. Meanwhile, the land use benefits calculated from housing prices, number of households and the proportion of green area are higher with the PA than with the AA in less competitive areas. This is because the PA leads to higher housing prices in these areas and thus produces much higher land use benefits.

When the two policy measures are applied in the more competitive areas, a greater number of trips are generated by all travel modes with AA than with PA. Consumer surplus and operator surplus are thus higher with AA, while government costs and externalities are lower.

\section{Conclusions}

This study focuses on the assessment of accessibility impacts using a LUTI model with two main innovations. The first is the use of the AA indicator to adjust the PA by incorporating the effect of competition among jobs. The second is the selection of the optimal value of the different policy measures that maximise the objective function based on PA and AA, analysing the results in terms of the CBA.

Two different policy measures (cordon toll and increased bus frequency) were optimised and evaluated by the LUTI model using PA and AA respectively. The results show that both policy measures reduce congestion and enhance the accessibility level in Madrid. However, social welfare is higher when applying a combination of measures than with the single policy, regardless of the accessibility indicators considered, thereby indicating that the combined policy is more effective in both cases.

In S2, the choice of the accessibility indicator in the optimisation process leads to a significant difference in two main elements of the objective function: consumer surplus and land-use costs. In fact, accessibility is an input/output for the land-use submodel and has an indirect effect on the welfare objective function. Particularly, the PA tends to produce a higher accessibility level in less competitive zones and thus an increase in car trips with PA as opposed to AA. The trips generated using the PA indicator produce a higher loss of consumer surplus. The land-use costs are also higher when using the PA; in fact, the PA indicator leads to higher house prices in less competitive areas. Therefore the proposed improvement in the accessibility indicator (AA) by introducing a territorial characteristic such as the competition factor represents a more realistic way of measuring the impacts on mobility patterns in areas with higher levels of jobs and workers. The inclusion of the AA indicator in the policy scenario analysis provides policy makers with a new tool for assessing the effects of transport policies.

\section{References}

Badoe, D. A., \& Miller, E. J. (2000). Transportation land-use interaction empirical findings in North America and their implications for modeling. Transportation Research D: Transport Environment, 5, 235-263.

Bertolini, L., Le Clercq. F., \& Kapoen, L. (2005). Sustainable accessibility: A conceptual framework to integrate transport and land use plan-making. Two test applications in the Netherlands and a reflection on the way forward. Transport Policy, 12, 207-220.

Brent, R. P. (1973). Algorithms for minimization without derivatives. Toronto: Prentice-Hall (chap. 3).

Condeço, A., Gutiérrez, J., \& Garcia, J. C. (2011). Spatial impacts of road pricing: Accessibility, regional spillovers and territorial cohesion. Transportation Research Part A, 45, 185-203.

C. T. R. M., (1998). EDM'96: Encuesta domiciliaria de movilidad en día laborable 1998.

C. T. R. M., (2006). EDM'04: Encuesta domiciliaria de movilidad en día laborable 2004.

Di Ciommo F., Monzón, A., Valdés. C., \& Wang. Y. (2011). A methodology to evaluate a toll-ring implementation in terms of metropolitan equity. The case of Madrid Metropolitan Area. Transportation Research Board 90th, Compendium of papers.

Geurs, K. T., \& Ritsema van Eck, J. R. (2003). Accessibility evaluation of land-use scenarios: the impact of job competition land-use and infrastructure developments for the Netherlands. Environment and Planning B, 30(1), 69-87.

Geurs, K. T., \& Van Wee, B. (2004). Accessibility evaluation of land-use and transport strategies: Review and research directions. Journal of Transport Geography, $12(2), 127-140$.

Geurs, K. T., Zondag, B., De Jong, G. C., \& De Bok, M. (2010). Accessibility appraisal of land use/transport policy strategies: More than just adding up travel-time savings. Transportation Research Part D, 15(7), 382-393.

Gutierrez, J., Monzón, A., \& Piñero, J. M. (1998). Accessibility, network efficiency and transport infrastructure planning. Environment and Planning A, 30, 1337-1350.

Guzmán L. A. (2011). Optimización dinámica de estrategias de movilidad sostenible en áreas metropolitanas (Doctoral dissertation, Caminos).

Guzmán, L. A., Di Ciommo F., \& De la Hoz, D. (2013). Congestion pricing and intertemporal preferences rate integration in social welfare function. Transportation Research Board 92th, Compendium of papers.

Haken, H. (1983). Advanced synergetics instability hierarchies of self-organizing systems and devices. Berlin: Springer (chap. 2).

Handy, S. (1994). Regional versus local accessibility: Implications for non-work travel. Transportation Research Record, 1400, 58-66.

Hansen, W. G. (1959). How accessibility shapes land use. Journal of American Institute of Planners, 25(1), 73-76.

INE. (2004, 2011). Instituto Nacional de Estadística. <http://www.ine.es/>.

Janamanchi, B., \& Burns, J. R. (2007). Reducing bullwhip oscillation in a supply chain: A system dynamics model-based study. International Journal of Information Systems and Change Management, 2(4), 350-371.

Joseph, A. E., \& Bantock, P. R. (1982). Measuring potential physical accessibility to general practitioners in rural areas: A method and case study. Social Science and Medicine, 16, 85-90.

Knox, P. L. (1978). The intraurban ecology of primary medical care: Patterns of accessibility and their policy implications. Environment and Planning A, 10, 415-435. 
Koenig, J. G. (1980). Indicators of urban accessibility: Theory and applications. Transportation, 9, 145-172.

Langford, M., Higgs, G., Radcliffe, J., \& White, S. (2008). Urban population distribution models and service accessibility estimation. Computers Environment and Urban Systems, 32(1), 66-80.

Lewis, R. M., Torczon, V., \& Trosset, M. W. (2000). Direct search methods: Then and now. Journal of Computational and Applied Mathematics, 124(1), 191-207.

Monzón, A., \& De la Hoz, D. (2009). Efectos sobre la movilidad de la dinámica territorial de Madrid. Urban, 14, 58-71.

Omer, I. (2006). Evaluating accessibility using house-level data: A spatial equity perspective. Computers, Environment and Urban Systems, 30(3), 254-274.

Pfaffenbichler, P., Emberger, G., \& Shepherd, S. (2010). A system dynamics approach to land use transport interaction modelling: The strategic model MARS and its application. System Dynamics Review, 26(3), 262-282.

Powell, M. J. D. (1964). An efficient method for finding the minimum of a function of several variables without calculating derivatives. The Computer Journal, 7(2), $155-162$.

Press, W. H., Teukolsky, S. A., Vetterling, W. T., \& Flannery, B. P. (1992). Numerical recipes in C: the art of scientific computing. 2. Cambridge: CUP (Chapter 7).

Shepherd, S. P., Zhan, X., Emberger, G., Huds, M., May, A. D., \& Paulley, N. (2006). Designing optimal urban transport strategies: The role of individual policy instruments and the impact of financial constraints. Transport Policy, 13(1), 49-65.

Singh, R. (1999). Improved speed-flow relationships: Application to transportation planning models. In 7th TRB conference on application of transport planning methods, Boston, Massachusetts.

Souto Nieves, G. (2003). Tasas de descuento para la evaluación de inversiones públicas: estimaciones para España. Instituto de Estudios Fiscales: Dirección General de Investigación de la Generalitat de Catalunya. Barcelona.

Sterman, J. D. (2000). Business dynamics: Systems thinking and modeling for a complex world (Vol. 19). New York: Irwin/McGraw-Hill.

Thill, J. C., \& Kim, M. (2005). Trip making, induced travel demand, and accessibility. Journal of Geographical Systems, 7(2), 229-248.

Van Wee, B., Hagoort, M., \& Annema, J. A. (2001). Accessibility measures with competition. Journal of Transport geography, 9, 199-208.

Weibull, J. W. (1976). An axiomatic approach to the measurement of accessibility. Regional Science and Urban Economics, 6, 357-379.

Yücel, G., \& Barlas, Y. (2007). Pattern-based system design/optimization. In Proceedings of the 25th International Conference of the System Dynamics Society, Boston. 